\title{
Presentación del monográfico Potencialidades y limitaciones de las cooperativas en Cuba (II)
}

Al presentar este nuevo monográfico de la revista Deusto Estudios Cooperativos dedicado a Cuba, no podemos menos que dedicar parte de estas líneas a honrar al profesor Fernández PeIso (1945-2019), quien fuera el Pionero del Derecho Cooperativo cubano, y cuyo deceso nos sorprendió hace tan solo unos meses.

La labor profesional de Avelino fue sumamente activa, desempeñándose -entre otras funciones- como Profesor de Derecho en la Universidad de Cienfuegos desde 1995 hasta su muerte. En su meritoria carrera alcanzó la categoría docente de Profesor Titular y obtuvo el grado científico de Doctor en Ciencias Jurídicas por la Facultad de Derecho de la Universidad de la Habana (2005). Entre sus múltiples publicaciones se cuentan dos libros de obligada referencia para quienes se adentren en el estudio de las cooperativas cubanas: "Lecturas en pro del Cooperativismo» (2008) y "La Cooperativa. Bases para su Legislación en Cuba» (2012). Fundador de la Unión Nacional de Juristas de Cuba y ponente en más de una treintena de eventos científicos nacionales e internacionales. Contaba con varias distinciones y reconocimientos, entre los que destacan el de Jurista Destacado a Nivel Nacional en 2008 y la Medalla 30 Aniversario de la Constitución de la República.

Más allá de estos justos reconocimientos profesionales, en una nota más personal, los juristas y los cooperativistas cubanos en general, tenemos con el profesor Fernández Peiso una deuda eterna. Su obra, ha sido faro para quienes trabajamos por un Derecho Cooperativo para Cuba. Su persona, de reposada y accesible sabiduría, nos ofreció el acompañamiento generoso y certero. Por todo ello, contará Avelino con un espacio privilegiado en la memoria colectiva. 
Respecto a los artículos que incluye este monográfico, el punto de partida está a cargo - precisamente- del Dr. C. Avelino FernándeZ PEISO con «EL ASUNTO COOPERATIVO EN CUBA. PERSPECTIVAS». Este trabajo inédito, si bien fue escrito por el autor hace ya algún tiempo, con motivo de su presentación en el I Taller Internacional de Derecho Cooperativo (COODER), celebrado en la Universidad de Pinar del Río los días 1, 2 y 3 de marzo de 2017, conserva plena vigencia. Alerta respecto al estado legal de la cooperativa en Cuba, que continúa desarrollándose en un ambiente institucional fracturado entre lo agropecuario y lo no agropecuario, sentado en normas legales no expresivas de su naturaleza social y aún pendiente de una Ley General de Cooperativas, asunto de suprema trascendencia para el proyecto socialista cubano.

A continuación, se suma a la mirada sobre las cooperativas cubanas una visión externa, siempre diferente y siempre necesaria. Héctor MATA DIESTRO ofrece sUS «PERSPECTIVAS PARA UN COOPERATIVISMO SOCIALISTA INTEGRAL CON BASE EN LOS VALORES Y PRINCIPIOS PROMOVIDOS POR LA CONSTITUCIÓN CUBANA». Este autor, como doctorando de la Universidad de Deusto, realizó una estancia de investigación de 3 meses en la Universidad de Pinar del Río (Cuba) entre noviembre de 2018 y febrero de 2019, lo cual le permitió enriquecer de primera mano sus ya amplios conocimientos sobre las cooperativas cubanas. Ahora nos ofrece sus agudas reflexiones, promoviendo una interpretación garantista del nuevo texto constitucional cubano que permita un desarrollo efectivo e integral del fenómeno cooperativo en el país, en el marco del proceso de actualización del modelo socioeconómico nacional.

Por su parte, el Dr. C. Orestes RodríGuez MusA, de la Universidad de Pinar del Río, en su trabajo apuesta por "LA ASESORÍA JURÍDICA EN POS DE LA IDENTIDAD COOPERATIVA. Potenciales contribuciones a las Cooperativas No Agropecuarias cubanas», en tanto estas formas asociativas presentan dificultades que las apartan de la identidad cooperativa universalmente reconocida. De cara a los principios cooperativos, y a las recientes transformaciones legislativas implementadas en el país para el sector, la asesoría jurídica puede contribuir en este sentido.

El cuarto artículo, relativo a «LA ACTIVIDAD REGISTRAL RELATIVA A LAS COOPERATIVAS EN CUBA. Perspectivas para su desarrollo», de la Dra. C. Orisel Hernández Aguilar, también de la Universidad de Pinar del Río, fundamenta algunos presupuestos que sirven de guía para contribuir al perfeccionamiento de la actividad registral relativa a las cooperativas en Cuba. Este empeño coincide con los esfuerzos del país en tal dirección, puesto que han sido promulgadas normas nuevas para los distintos ámbitos del cooperativismo nacional en las que se han es- 
tablecido las bases para una progresiva unificación del sistema registral de estos entes.

Novedoso enfoque desde las Ciencias Psicológicas nos ofrecen Deibby Valle Ríos (Universidad de Pinar del Río, Cuba) y José Manuel FlGUEROA GonzÁlez (Escuela de Administración de Empresas, España) respecto a la "PERCEPCIÓN SOCIAL DE LOS SOCIOS SOBRE LAS COOPERATIVAS NO AGROPECUARIAS EN CUBA», donde se fundamentan los elementos teóricos relacionados con los procesos de percepción y percepción social, y los modos en que se ha estudiado el tema desde las cooperativas. Para ello, se tienen en cuenta los avances de la provincia de Pinar del Río en el tema, y se diagnostica la percepción social que poseen los miembros de las Cooperativas No Agropecuarias en Cuba. También de este trabajo destaca la mirada externa de FigueroA GonZÁlez quien, pese a su condición de cubano y su constante vinculación con el contexto nacional, reside en Barcelona desde hace más de 20 años.

Por último, cierra Yaumara Acosta Morales de la Universidad de Cienfuegos, con la necesaria mirada hacia las «COOPERATIVAS AGROPECUARIAS: UN FACTOR INDISPENSABLE PARA LA SOBERANÍA ALIMENTARIA EN CUBA», considerándolas como empresas vinculadas de forma estable al territorio rural y al productor agroalimentario, que ejercen el liderazgo en la economía de estas áreas y en la fijación de población en municipios rurales. Desde este discurso, contribuye al equilibrio, la ordenación y el desarrollo rural.

Orestes Rodríguez Musa Universidad de Pinar del Río, Cuba 


\section{Derechos de autor}

La revista Deusto Estudios Cooperativos es una revista de acceso abierto lo que significa que es de libre acceso en su integridad inmediatamente después de la publicación de cada número. Se permite su lectura, la búsqueda, descarga, distribución y reutilización legal en cualquier tipo de soporte sólo para fines no comerciales y según lo previsto por la ley; sin la previa autorización de la Editorial (Universidad de Deusto) o el autor, siempre que la obra original sea debidamente citada (número, año, páginas y DOI si procede) y cualquier cambio en el original esté claramente indicado.

\section{Copyright}

The Deusto Journal of Cooperative Studies is an Open Access journal which means that it is free for full and immediate access, reading, search, download, distribution, and lawful reuse in any medium only for non-commercial purposes, without prior permission from the Publisher or the author; provided the original work is properly cited and any changes to the original are clearly indicated. 